\title{
Analisa Perbandingan Squid 2.7, Squid3, Dan Squid Lusca Sebagai Cache Proxy Server Pada Ubuntu Server
}

\author{
Gilang Ferdiansyah' $^{1)}$, Kustanto ${ }^{2)}$, Sri Hariyati Fitriasih ${ }^{3)}$ \\ 1) Program Studi S1 Informatika, STMIK Sinar Nusantara \\ 2) Program Studi D3 Teknologi Informasi, STMIK Sinar Nusantara \\ 3) Program Studi D3 Sistem Informasi, STMIK Sinar Nusantara \\ 1)gilang_id@ymail.com; 2)kustanto@sinus.ac.id; 3)fitri@sinus.ac.id
}

\begin{abstract}
$R T / R W$ Net Joho Baru is one of the internet service provider organizations. As one of the growing internet service provider RT/RW Net Joho Baru has to give the best and the quickest services to the customers. So that it need appropriate technology which is support to the best networks to give good services to the customers. The Important factors are cost and speed factors which related to the material efficiency and time. This research is comparing about proxy server operating systems such as Squid 2.7, Squid3, and Squid Lusca, so that it can easier to find out the appropriate operating systems to build the best network. SDLC Method has several steps. The first step is the analysis of feasibility study which included software and hardware. The second step is the analysis of needs which is planning relate to the system project. Then network planning design is going apply. Next, continuing design system to system testing. Based on these steps, the proxy server is successfully to shorten time management on accessing the website. The results of the efficiency acquisition are Squid 2.7 at 75,1\%, Squid3 at 83,5\%, and Squid Lusca at 86,9\%.
\end{abstract}

Keywords: Network Operating System, Proxy Server, Service Squid

\section{PENDAHULUAN}

RT/RW Net Joho Baru merupakan salah satu organisasi penyedia layanan internet. Sebagai penyedia jasa internet yang terus berkembang, RT/RW Net Joho Baru dituntut untuk memberikan pelayanan internet yang baik dan cepat. Untuk itu diperlukan teknologi yang mendukung dan jaringan yang baik dalam penyediaan performa internet yang baik kepada pelanggan.

Hal yang menjadi masalah dalam ISP atau RT/RW (Rukun Tetangga / Rukun Warga) Net adalah penyediaan sumber daya bandwidth dan juga kecepatan akses internet. Semakin banyaknya pelanggan ISP / RT/RW Net, tentunya membutuhkan bandwidth yang cukup besar. Pelanggan dengan pengguna internet seperti volume surfing atau browsing di internet yang cukup besar, mendownload file-file berukuran besar, dan streaming video dari web sharing video yang tentu saja membutuhkan bandwidth yang cukup besar. Dengan bandwidth yang cukup besar ini tentu menciptakan biaya yang cukup besar juga untuk pembelian bandwidth pada RT/RW Net Joho Baru. Kecepatan akses internet juga sering dipertanyakan oleh user RT/RW Net Joho Baru yang terkadang mengharapkan akses yang lebih cepat dalam internet. Padahal masalah kecepatan akses internet tidak hanya dikarenakan oleh kecepatan yang diberikan oleh RT/RW Net Joho Baru tetapi bisa saja web server yang diakses oleh pengguna mengalami overload sehingga user melimpahkan beban kesalahan terhadap pengguna jasa internet.

Dari berbagai sistem operasi yang telah ada, tentunya memiliki kekurangan dan kelebihan. Untuk itu diperlukan kejelian untuk memilih sistem operasi proxy server yang sesuai untuk mengoptimalkan kinerja server dan jaringan itu sendiri. Dengan adanya perbandingan dari beberapa sistem operasi proxy server dan terdapat bukti yang otentik berupa data dari hasil penelitian, maka akan lebih mempermudah untuk menentukan sistem operasi mana yang sesuai dengan jaringan yang nantinya akan mempengaruhi dari kinerja proxy server.

Berdasarkan informasi tersebut, maka dalam penelitian ini penulis mengambil suatu topik penelitian yaitu mengenai "Analisa Perbandingan Squid3, Squid 2.7, dan Squid Lusca sebagai Cache Proxy Server pada Ubuntu Server".

\section{TINJAUAN PUSTAKA}

Penelitian penggunaan proxy squid di CV. Nusantara Geotech Makassar. Dalam sistem ini peralatan yang dipakai menggunakan proxy software yang dipercaya dapat bekerja pada 
peralatan hardware ataupun pada komputer yang digunakan. Sistem keamanan dan privasi dijalankan dengan menggunakan dua buah protokol terpisah. Sebuah protokol untuk komunikasi alat ke proxy yang aman, dan sebuah protokol untuk komunikasi proxy-proxy yang aman. Penelitian ini merupakan penelitian pengembangan perangkat lunak yang dilakukan dengan melakukan konfigurasi squid.conf untuk membatasi kecepatan mengunduh dari pengguna, web filtering melalui Access Control List (ACL) untuk membatasi situs web yang dapat diakses dan implementasi local cache Squid yang terhubung dengan proxy server di CV. Nusantara Geotech mempercepat membuka situs web yang sering diakses. [1]

Pada penelitian pemanfaatan proxy squid sebagai media penyimpanan sementara atau caching pada jaringan. Penelitian ini menggunakan software Squid3 dengan memanfaatkan aplikasi distro Linux Ubuntu Server 14.04. Fasilitas caching dapat menyimpan akses dari internet ke dalam harddisk pada proxy server, sehingga untuk akses ulang akan lebih mudah. Hasil dari penelitian ini dapat digunakan sebagai proxy server external dalam jaringan komputer, dengan proxy server juga dapat memanajemen bandwitdh serta filtering akses website. [2]

Penelitian yang menerapkan proxy server pada jaringan hotspot. Penelitian ini membuat proxy server dengan menggunakan Squid sebagai aplikasi utama didukung oleh paketpaket lain dengan menggunakan sistem operasi linux. Dalam melakukan pengembangan sistem ini, penulis berusaha untuk membangun proxy server sendiri dengan memanfaatkan fasilitas yang ada dan sudah ada di Universitas Putra Indonesia "YPTK" Padang [3]

Penelitian yang bertemakan analisis dan rancang bangun system layanan proxy server pada SMK Unggul Sakti Jambi. Memanfaatkan proxy server untuk mengamankan akses informasi yang terhindar dari informasi yang tidak baik. Sistem layanan proxy server berperan sebagai salah satu alternative yang handal dalam menciptakan akses internet yang sehat. Layanan proxy server menggunakan system operasi Linux Debian 6 dan aplikasi proxy menggunakan squid. Secara fungsional system dapat melakukan pemblokiran namanama sistus terlarang dan dapat memblokir kata kunci pencarian yang mengandung makna pornografi, namun pengujiannya belum sempurna, karena baru dilakukan pada satu sisi pemblokiran saja sedangkan mengenai unjuk kerja proxy server belum dilakukan. [4]

Penelitian yang bertemakan analisa traffic jaringan menggunakan squid proxy server untuk peningkatan performa akses internet di universitas Madura. Pada kegiatan ini dilakukan implementasi squid sebagai proxy server internet. Hasil yang didapatkan adalah akses internet yang lebih cepat dan meningkatkan kinerja, baik bagian akademik maupun bagian administrasi.[5]

\section{METODE PENELITIAN}

Metode penelitian yang digunakan adalah metode SDLC (System Development Lyfe Cycle). Metode SDLC yang digunakan meliputi beberapa fase, fase pertama yaitu analisa. Analisa yang dilakukan meliputi analisa studi kelayakan termasuk sumber daya manusia yang menggunakan serta software dan hardware yang digunakan. Fase yang kedua adalah analisa kebutuhan, yaitu melakukan perincian mengenai apa saja yang dibutuhkan dalam pengembangan sistem dan membuat perencanaan yang berkaitan dengan proyek sistem. Selanjutnya adalah fase desain jaringan yang akan diterapkan. Setelah menentukan desain jaringan dilanjutkan dengan perancangan sistem hingga pengujian sistem. Selain itu juga menggunakan metode statistik untuk membandingan data antar percobaan guna mencari keunggulan pada objek percobaan.

Pada tahap awal dilakukan analisa sistem yang sudah berjalan meliputi studi kelayakan SDM serta ketersediaan bandwitdh dan desain jaringan yang telah ada. Kemudian dilanjutkan dengan analisa kebutuhan yaitu melihat kondisi jaringan yang ada termasuk hardware dan software yang digunakan. Tahap selanjutnya dilakukan desain jaringan yang digunakan ketika penerapan sistem proxy dilakukan adalah dengan memasang proxy server sejajar dengan router distribusi yang digunakan untuk mengatur jaringan dan mengalokasikan bandwidth yang disalurkan menuju klien. Dilanjutkan dengan langkah perancangan proxy server melalui beberapa tahap, serta konfigurasi server dan pengujian dari implementasi proxy server.

\section{HASIL DAN PEMBAHASAN}

Pengujian yang dilakukan pada penelitian ini adalah dengan melakukan browsing dari 3 klien mengakses 3 website yang sudah ditentukan. Berikut adalah waktu tempuh rata - 
rata dari 5 kali pengaksesan masing - masing website tanpa menggunakan proxy server seperti yang ditampilkan di Tabel 1 .

Tabel 1 Tabel Percobaan tanpa menggunakan proxy server.

\begin{tabular}{|l|l|l|l|l|l|l|}
\hline Percobaan & $\begin{array}{l}\mathrm{I} \\
(\mathrm{ms})\end{array}$ & $\begin{array}{l}\text { II } \\
(\mathrm{ms})\end{array}$ & $\begin{array}{l}\text { III } \\
(\mathrm{ms})\end{array}$ & $\begin{array}{l}\text { IV } \\
(\mathrm{ms})\end{array}$ & $\begin{array}{l}\text { V } \\
(\mathrm{ms})\end{array}$ & $\begin{array}{l}\text { Rerata } \\
(\mathrm{ms})\end{array}$ \\
\hline www.yahoo.com & 61,6 & 61,7 & 60,9 & 60,8 & 61,7 & 61,34 \\
\hline www.kompas.com & 30,2 & 5,5 & 5,6 & 5,8 & 6 & 10,62 \\
\hline www.okezone.com & 19 & 10,8 & 16 & 8 & 12,6 & 13,28 \\
\hline
\end{tabular}

Diatas merupakan hasil waktu tempuh sebanyak 5 kali percobaan pada pengaksesan 3 website tanpa menggunakan proxy server. Dan selanjutnya dilakukan percobaan yang sama dengan menggunakan proxy server yang akan diuji.

Hasil rata - rata waktu tempuh tanpa menggunakan proxy server pada tabel diatas digunakan sebagai perbandingan ketika mengakses website yang sama dengan menggunakan proxy squid3, squid 2.7, dan lusca. Berikut adalah hasil pengujian rata-rata dari 5 kali mengakses website dengan menggunakan proxy squid3, squid 2.7, dan lusca.

Tabel 2 Percobaan menggunakan proxy server Squid2.7.

\begin{tabular}{|l|l|l|l|l|l|l|}
\hline Percobaan & $I(\mathrm{~ms})$ & $\|$ (ms) & $I I(\mathrm{~ms})$ & $\begin{array}{l}\text { IV } \\
(\mathrm{ms})\end{array}$ & V(ms) & $\begin{array}{l}\text { Rerata } \\
(\mathrm{ms})\end{array}$ \\
\hline www.yahoo.com & 11 & 12,9 & 8,14 & 9,13 & 9,56 & 10,15 \\
\hline www.kompas.com & 6,27 & 7,14 & 6,83 & 6,56 & 5,76 & 6,51 \\
\hline www.okezone.com & 11,4 & 9,13 & 8,4 & 9,4 & 8,02 & 9,27 \\
\hline
\end{tabular}

Tabel 3 Percobaan menggunakan proxy server Squid 3.

\begin{tabular}{|l|l|l|l|l|l|l|}
\hline Percobaan & $I(\mathrm{~ms})$ & $\begin{array}{l}\| \\
(\mathrm{ms})\end{array}$ & $\begin{array}{l}\text { III } \\
(\mathrm{ms})\end{array}$ & $\begin{array}{l}\text { IV } \\
(\mathrm{ms})\end{array}$ & $\begin{array}{l}\text { V } \\
(\mathrm{ms})\end{array}$ & $\begin{array}{l}\text { Rerata (m } \\
\text { s) }\end{array}$ \\
\hline www.yahoo.com & 15,9 & 21,7 & 14,5 & 13,9 & 10,5 & 15,30 \\
\hline www.kompas.com & 14,2 & 6,3 & 6,25 & 6 & 7,23 & 8,00 \\
\hline www.okezone.com & 12,4 & 10 & 9 & 7,22 & 12,1 & 10,14 \\
\hline
\end{tabular}

Tabel 4 Percobaan menggunakan proxy server Squid Lusca.

\begin{tabular}{|c|c|c|c|c|c|c|}
\hline Percobaan & $I(\mathrm{~ms})$ & $\|(m s)$ & $1 \|$ (ms) & \begin{tabular}{|l|} 
VV \\
(ms)
\end{tabular} & $V(m s)$ & \begin{tabular}{|l|} 
Rerata \\
$(\mathrm{ms})$
\end{tabular} \\
\hline wWw.yahoo.com & 8,67 & 11 & 7,31 & 5,41 & 7,9 & 8,06 \\
\hline WWw.kompas.com & 6,2 & 5,07 & 6,47 & 7,37 & 5,69 & 6,16 \\
\hline www.okezone.com & 9,33 & 5,28 & 8,12 & 8,43 & 6,81 & 7,59 \\
\hline
\end{tabular}

Tabel 1- 4 merupakan hasil perbandingan 5 kali percobaan pada 3 macam proxy server yang digunakan dalam penelitian. Dilihat dari waktu yang dapat ditempuh dari ketiga proxy ketika mengakses website tanpa menggunakan proxy server dan dengan menggunakan proxy server. Data dari hasil setiap pengujian waktu yang dapat ditempuh masing - masing proxy server dapat diperjelas menggunakan grafik pada Gambar 1.

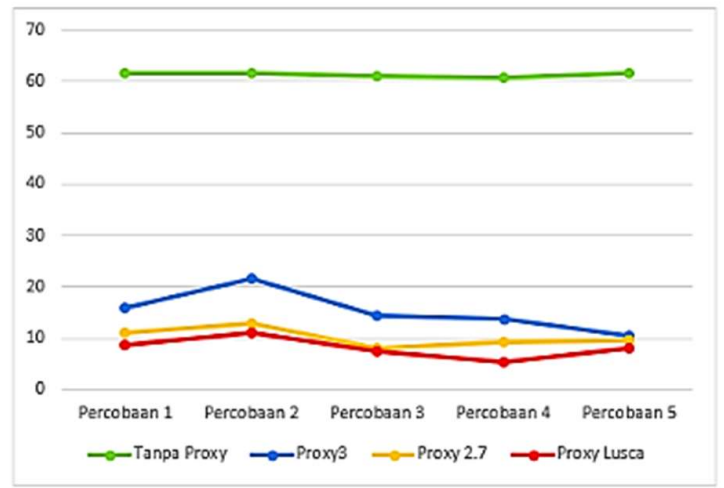

Gambar 1. Grafik waktu tempuh proxy server saat mengakses www.yahoo.com.

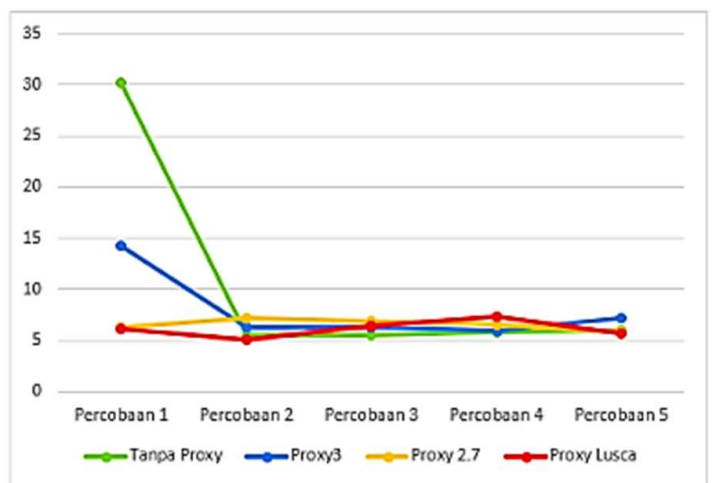

Gambar 2. Grafik waktu tempuh proxy server saat mengakses www.kompas.com.

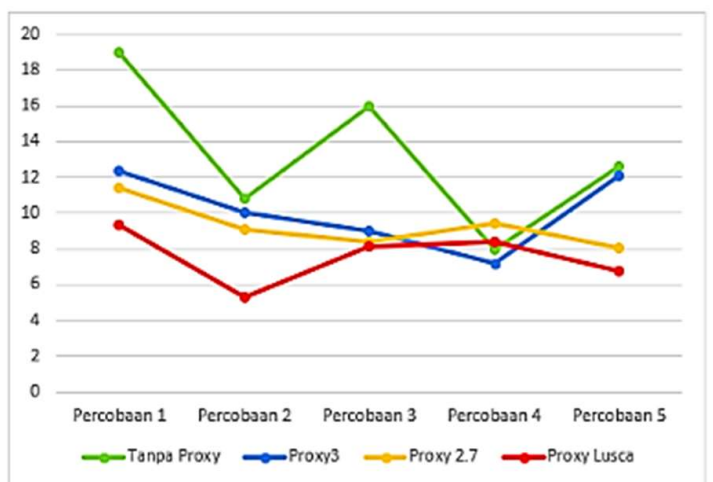

Gambar 3. Grafik waktu tempuh proxy server saat mengakses www.okezone.com.

Untuk mengukur selisih waktu yang butuhkan dapat dihitung dengan rumus sebagai berikut:

$$
S W=S B C-S S C
$$

Keterangan:

SW : Selisih Waktu (Detik)

SBC : Sebelum Menggunakan Proxy (Detik)

SSC : Setelah Menggunakan Proxy (Detik) 
Sedangkan untuk mengukur persentase efsiensi waktu yang dibutuhkan dapat dihitung dengan rumus sebagai berikut:

Keterangan:

$$
P E W=\frac{S W}{S S C} \times 100 \%
$$

PEW : Persentase Efektiftas Waktu (\%)

SW : Selisih Waktu (detik)

SBC : Sebelum Menggunakan Proxy (Detik)

Menggunakan rumus diatas untuk mencari efisiensi performa dari masing - masing proxy. Berikut adalah hasil perhitungan efisiensi menggunakan rumus diatas

Tabel 5. Selisih Waktu dan Persentase Efisiensi pada saat menggunakan Squid 2.7

\begin{tabular}{|l|l|l|l|l|}
\hline & $\begin{array}{l}\text { Rerata tanpa } \\
\text { proxy (SBC) }\end{array}$ & $\begin{array}{l}\text { Rerata Squid } \\
2.7(\text { SSC) }\end{array}$ & $\begin{array}{l}\text { Efisiensi } \\
\text { Wakku (SW) }\end{array}$ & $\begin{array}{l}\text { Persentase } \\
\text { Efektittas } \\
\text { Wakktu }\end{array}$ \\
\hline www.yahoo.com & $61,34 \mathrm{~ms}$ & $15,3 \mathrm{~ms}$ & $46,04 \mathrm{~ms}$ & $75,1 \%$ \\
\hline www.kompas.com & $10,62 \mathrm{~ms}$ & $7,996 \mathrm{~ms}$ & $2,624 \mathrm{~ms}$ & $24,7 \%$ \\
\hline www.okezone.com & $13,28 \mathrm{~ms}$ & $10,144 \mathrm{~ms}$ & $3,136 \mathrm{~ms}$ & $23,0 \%$ \\
\hline
\end{tabular}

Tabel 6. Selisih Waktu dan Persentase Efisiensi pada saat menggunakan Squid3

\begin{tabular}{|l|l|l|l|l|}
\hline & $\begin{array}{l}\text { Rerata tanpa } \\
\text { proxy }(S B C)\end{array}$ & $\begin{array}{l}\text { Rerata Squid3 } \\
(S S C)\end{array}$ & $\begin{array}{l}\text { Efisiensi } \\
\text { Waktu (SW) })\end{array}$ & $\begin{array}{l}\text { Persentase } \\
\text { Efekititas } \\
\text { Wakku }\end{array}$ \\
\hline wWw.yahoo.com & $61,34 \mathrm{~ms}$ & $10,146 \mathrm{~ms}$ & $51,19 \mathrm{~ms}$ & $83,5 \%$ \\
\hline wWw.kompas.com & $10,62 \mathrm{~ms}$ & $6,512 \mathrm{~ms}$ & $4,108 \mathrm{~ms}$ & $38,7 \%$ \\
\hline wWw.okezone.com & $13,28 \mathrm{~ms}$ & $9,27 \mathrm{~ms}$ & $4,01 \mathrm{~ms}$ & $30,2 \%$ \\
\hline
\end{tabular}

Tabel 7. Selisih Waktu dan Persentase Efisiensi pada saat menggunakan Squid Lusca

\begin{tabular}{|l|l|l|l|l|}
\hline & $\begin{array}{l}\text { Rerata tanpa } \\
\text { proxy (SBC) }\end{array}$ & $\begin{array}{l}\text { Rerata Squid } \\
\text { Lusca (SSC) }\end{array}$ & $\begin{array}{l}\text { Efisiensi } \\
\text { Wakku (SW) }\end{array}$ & $\begin{array}{l}\text { Persentase } \\
\text { Efektittas } \\
\text { Wakktu }\end{array}$ \\
\hline www.yahoo.com & $61,34 \mathrm{~ms}$ & $8,058 \mathrm{~ms}$ & $53,282 \mathrm{~ms}$ & $86,9 \%$ \\
\hline www.kompas.com & $10,62 \mathrm{~ms}$ & $6,16 \mathrm{~ms}$ & $4,46 \mathrm{~ms}$ & $42,0 \%$ \\
\hline www.okezone.com & $13,28 \mathrm{~ms}$ & $7,594 \mathrm{~ms}$ & $5,686 \mathrm{~ms}$ & $42,8 \%$ \\
\hline
\end{tabular}

Cache proxy server membantu dalam akses internet. Terutama menyimpan file website yang telah diakses oleh klien kemudian meload kembali file dari website tersebut ketika ada request yang sama. Proxy server baik Squid3, Squid 2.7, maupun Lusca yang dimanfaatkan sebagai cache proxy mampu menyimpan file website yang diakses klien pada cache hardisk lokal, sehingga proxy server ini dapat diibaratkan sebagai asisten server utama yang menyediakan file yang diakses klien.

Berdasarkan penelitian yang telah dilakukan dari ketiga proxy server, delay yang dapat ditempuh dari masing - masing website yang diakses dipengaruhi juga oleh besarnya bandwidth yang didapatkan oleh klien. Ketika klien mendapatkan bandwidth yang cukup besar, efisiensi waktu yang dapat ditempuh dari pengaksesan suatu website tidak begitu terlihat atau terasa. Karena efisiensi waktu yang dapat ditempuh hanya sedikit sekali. Namun ketika bandwidth yang oleh klien kecil, cache proxy server akan sangat berpengaruh untuk pengaksesan suatu website.

\section{PENUTUP}

\subsection{Kesimpulan}

Berdasarkan pada pembahasan yang ada tentang perbandingan proxy server, dapat ditarik kesimpulan sebagai berikut.

1. Untuk membangun server dengan squid 2.7, squid3, ataupun lusca sebagai cache proxy mempunyai cara instalasi dan konfigurasi yang berbeda - beda.

2. Proxy server squid, squid3, dan lusca yang difungsikan sebagai cache proxy server dapat menyimpan file website yang telah diakses oleh suatu client. Hal ini berdampak mempercepat membuka halaman website yang dituju ketika file dari website yang diakses tersebut telah tersimpan didalam cache proxy server.

3. Performa dari squid, squid3, dan squid lusca sebagai cache proxy server samasama dapat memperpendek waktu yang dibutuhkan untuk mengakses suatu website.

\subsection{Saran}

1. Fitur - fitur yang ditawarkan oleh software proxy server sangatlah banyak dan beragam. Pada penelitian ini, penulis hanya memfungsikan proxy sebagai cache proxy server. Diharapkan pada penelitian selanjutnya dapat melakukan percobaan dengan memaksimalkan fungsi dari proxy server.

2. Software proxy server yang tersedia sangatlah banyak. Pada penelitian ini, penulis hanya membandingkan 3 software proxy server dengan 3 klien dan dari masing-masing klien hanya mengakses I website. Diharapkan pada penelitian selanjutnya untuk melakukan penelitian dengan percobaan lebih dari 3 software dan klien yang lebih lagi banyak supaya dapat memberikan infomasi yang lebih banyak tentang proxy server. 


\section{DAFTAR PUSTAKA}

[1] Rosihan Aminuddin, Moch. Apriyadi, "Perancangan Proxy Server Dengan Menggunakan Squid Di CV. Nusantara Geotech Makassar", J. Instek. Volume 2, Nomor 2, Oktober 2017. Universitas Patria Artha Makasar.

[2] Yuisar, Liza Yulianti, Yanolanda Suzantry $\mathrm{H}$, "Analisa Pemanfaatan Proxy Server Sebagai Media Filtering dan Caching Pada Jaringan Komputer", Jurnal Media Infotama. Volume 11, Nomor 1, Februari 2015. Universitas Dehasen Bengkulu.

[3] Yuhandri, "Penerapan Proxy Server Dengan Menggunakan Sistem Operasi Linux Pada Hotspot Universitas Putra Indonesia "YPTK" Padang", Jurnal Media Processor. Volume 8, Nomor 3, Oktober 2013. Universitas Putra Indonesia Padang.

[4] Santoso, "Analisis dan rancang bangun system layanan proxy server pada SMK Unggul Sakti Jambi", Jurnal Manajemen Sistem Informasi, Vol.2, No.1, Maret 2017, hal: 260-277, STIKOM Dinamika Bangsa Jambi.

[5] Khoiruddin dan Ubaidi "Analisa traffic jaringan menggunakan squid proxy server untuk peningkatan performa akses internet di universitas Madura", J. Insand Comtech, Vol. 6, No. 2, Oktober 2020.hal.15-22. 